\title{
Modeling of three-limb three-phase transformer relates to shunt core using in industrial microwave generators with $\mathbf{N}=2$ magnetron per phase
}

\author{
H. Outzguinrimt ${ }^{1}$, M. Chraygane ${ }^{2}$, M. Lahame ${ }^{3}$, R. Oumghar ${ }^{4}$, R. Batit Ou. Merfra $^{6}$ \\ 1,2,3,4,5 MSTI Team, ESTA, Technologie Higher School Agadir Ibn Zohr University, Morocco \\ ${ }^{6}$ Power Electronics Laboratory, EMI, Mohammadia Engineering school Mohamed V University, Morocco
}

\begin{tabular}{l} 
Article Info \\
\hline Article history: \\
Received Sep 5, 2018 \\
Revised Apr 26, 2019 \\
Accepted Jun 26, 2019 \\
\hline Keywords: \\
Magnetron \\
Matlab-simulink \\
Microwaves \\
Modeling \\
Power supply
\end{tabular}

\begin{abstract}
This paper describes the development and implementation of a digital simulation model of a three-phase transformer relates to shunt core transformer, which used to drive magnetron tubes in the microwave. The focus of this study is based on modeling of a new shell-type of three limbs three-phase transformer. The model uses to feed two magnetrons instead of one magnetron per phase. The proposed model is established on the simultaneous analysis of a duo electromagnetic lumped component equivalent circuit. This latter was implemented in a MATLAB environment under rated conditions. The results obtained from the application of the analytical method are provided results in conformity to the experimental tests in the case of single phase high voltage power supply for one magnetron.
\end{abstract}

Copyright $\odot 2019$ Institute of Advanced Engineering and Science. All rights reserved.

\section{Corresponding Author:}

Hamid Outzguinrimt,

Modeling, Systems, and Technologies of Information Team,

Ibn Zohr University,

High School of Technology, BP: 33/S 80000, Agadir, Morocco.

Email: hamid.outzguinrimt@edu.uiz.ac.ma

\section{INTRODUCTION}

The present transformer relates to shunt core becomes a very interesting research topic, and are well known, especially useful in the powering of magnetron tubes in a microwave. A three-phase transformer is realized by connecting three single-phase transformers or designed as a single unit [1-3]. This transformer model has a special structure and wide application [3, 4], compared with the ordinary transformer. The modeling of this transformer depends on different approaches [2,3,5]. The first idea is to develop a mathematical model based on an equivalent electrical circuit. Linear parameters as winding inductance and resistance can be determined easily [6,7]. Nonlinear behavior of magnetic core is usually included by using either nonlinear curves flux-current [8-10]. The obtained equations system establish the electric equivalent model on $\pi$ of the three-phase transformer with the shunt in the non-linear regime. This model is implanted in Matlab [11-12]. It is based on the fitting technique of magnetization curve B-H. It take into account the saturation phenomena but doesn't take in consideration the iron loss due to the hysteresis and eddy currents.

The importance of this work is to exploit the model of three-limb three-phase transformer power supply HV for microwave applications [2]. This study is used the model proposed and developed by $[1,3,13,14]$ to feed two magnetrons per phase instead of one. Consequently, determining the new dimensional of the transformer in order to find the most economical choice within respecting the limitations imposed by the constraint of the magnetron to avoid any overload. 
The main objective is to choose the design model of the magnetic flux leakage transformer. This design concerning a particular characteristic which is suitable, in the same time satisfies all constraints or limitation imposed on the performance of magnetrons. The new model requires new parameters dimensions, which should have capabilities to support two magnetron complex load characteristics. This has multiple benefits in terms of reducing weight, volume, electrical wiring and cost during the implementation and maintenance. It could reduce the development time and the cost of experiment prototype as much as possible. Then study the sensitivity of the current in each magnetron used, respecting the variations of the voltage in the supply network of the microwave generator processed.

\section{MODELING THREE-PHASE TRANSFORMER OF THE HIGH VOLTAGE POWER SUPPLY WITH TWO MAGNETRONS PER PHASE}

The aim of this section is to discuss a duo electric-magnetic circuit model of three-phase transformer HV power supply for microwave generators with two magnetrons per phase. The model uses a new shelltype transformer with a magnetic shunt [15-17]. Figure 1 presents the geometric shape of the magnetic circuit of this transformer, each phase contains two windings (primary and secondary) placed in the middle limb. Shunts core are identical and consist of a certain number of stacked sheets $n 3$, they are located between the primary and the secondary coil of each phase. These shunts are used to deflect a partition of the magnetic flux from the secondary coils, which serves to regulate the anode current in the magnetron, support the resonant circuit developed by the inductance of the transformer coils, and preventing over-driving of the magnetron. The model is explained in detail in the following sections.

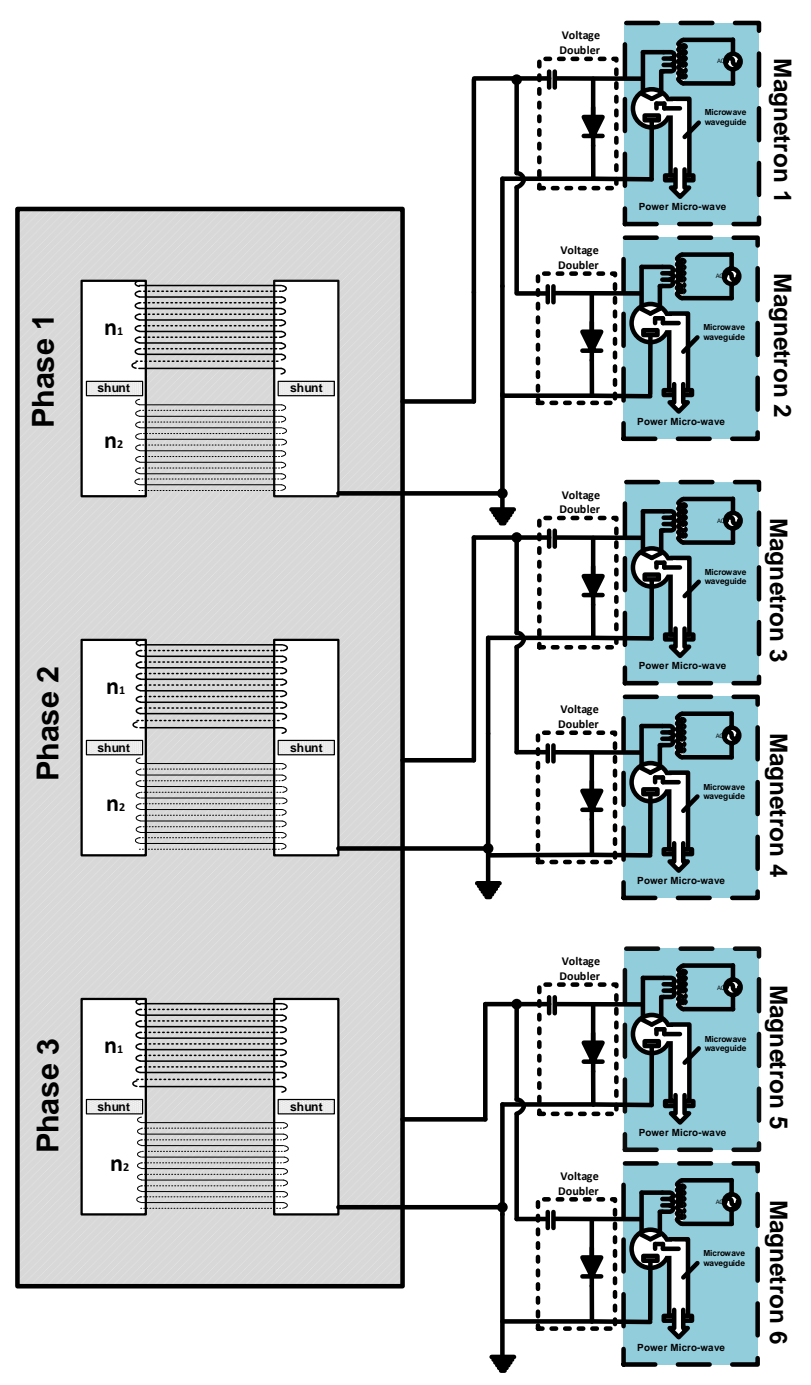

Figure 1. High voltage power supply for two magnetron by phase 


\subsection{Description of the model}

Figure 1 shows the schematic of the three-phase transformer power supply for two magnetrons per phase. The primary and the secondary coils of each phase are wound of insulated copper wire with the appropriate number of windings $\mathrm{n}_{1}$ and $\mathrm{n}_{2}$. The coils provide the desired voltages on the magnetron and handle the necessary current flow to provide the appropriate power to the magnetron.

The primary current input voltage $\mathrm{i} 1 \mathrm{j}$ is applied to the primary winding, and a varying flux $\phi$ is generated in the core. The secondary coil is wound around and in conjunction with the core, which generates the secondary current-voltage $i_{2 j}$ therein by the varying flux in the core and applied to the filament of magnetron. As is well known, the filament is heated thus and provides a source of electrons for the function of the magnetron.

The secondary coil is connected in series with a capacitor and across the diode, which composed together a double voltage, also across the filament and plate of magnetron [18, 19]. This applies the Radiofrequency (RF) DC voltage between the plate and filament of the magnetron causing a varying Radiofrequency electric field which, in conjunction with the magnetic field present in the magnetron. $r_{1 j}$ and $r_{2 j}$ represent the resistances of the primary and secondary windings for each phase of the transformer. $\phi_{1 \mathrm{j}}, \phi_{2 \mathrm{j}}$ and $\phi_{3 \mathrm{j}}$ are the flux magnetic of the primary, secondary side and the shunts of each phase respectively, where subscript $j$ denotes the phase.

\subsection{Equivalent circuit of transformer referred to secondary}

\subsubsection{Electrical equations}

Each turn of the primary circuit traversed by the flux is the seat of an electromotive force $e(t)$ of self-induction. It is the same for each turn of the secondary circuit. Each phase of the transformer primary winding is fed by an alternative source (AC). It flows in the magnetic circuit also an alternating flux $\varphi_{1 j}$ whose amplitude depends on the number of turns of the primary $n_{1}$ and the applied voltage $u_{1 j}$. This flux induces in the secondary winding a voltage proportional to the number of turns of the secondary $n_{2}$.

Consider the primary circuit. A voltage equation around the loop of phase $\mathrm{j}$ could be written as:

$$
u_{1 j}=r_{1 j} i_{1 j}+n_{1} \frac{d \phi_{1 j}}{d t}
$$

The secondary circuit is considered next. The voltage equation could be written as follows:

$$
u_{2 j}=-r_{2 j} i_{2 j}+n_{2} \frac{d \phi_{2 j}}{d t}
$$

In this case, to study the operation of this new model in the MATLAB code. All the quantities of the equivalent circuit $\pi$ model is referred to the secondary side. Thus, (1) rewrite to

$$
\begin{aligned}
& u_{1 j}^{\prime}=r_{1 j}^{\prime} i_{1 j}^{\prime}+\frac{d}{d t}\left(\frac{n_{2}^{2}}{\mathfrak{R}_{p j}} \frac{\Re_{p j} \cdot \phi_{1 j}}{n_{2}}\right) \\
& u_{1 j}^{\prime}=r_{1 j}^{\prime} i_{1 j}^{\prime}+\frac{d}{d t}\left(L_{p j}^{\prime} \cdot i_{p j}^{\prime}\right)
\end{aligned}
$$

In a similar way, the equation of the secondary:

$$
\begin{aligned}
& u_{2 j}=-r_{2 j} i_{2 j}+\frac{d}{d t}\left(\frac{n_{2}^{2}}{\mathfrak{R}_{s j}} \frac{\mathfrak{R}_{s j} \cdot \phi_{2 j}}{n_{2}}\right) \\
& u_{2 j}=-r_{2 j} i_{2 j}+\frac{d}{d t}\left(L_{s j} \cdot i_{s j}\right)
\end{aligned}
$$

\subsubsection{Magnetic equations}

For simplicity, we only model the right half of the transformer. We are based on the flux distribution, and taking advantage of the vertical symmetry of the transformer. It is possible to represent this model by an equivalent magnetic circuit as shown in following Figure 2, Figure 3, and Figure 4, consisting of magneto-motive forces, related with each winding primary and secondary. 
Ampere's circuit law relates the integrated magnetic field around a closed loop to the electric current passing through the loop.

$$
\oint \vec{H} \cdot \overrightarrow{d \ell}=N \cdot i
$$

Where $\vec{H}$ is the magnetic field intensity, $\overrightarrow{d \ell}$ is the differential of length $\vec{H} \cdot \overrightarrow{d \ell}$ is the product of the tangential component of $\mathrm{H}$ and the incremental distance $d \ell$ along the path, this equation can be written as

$$
\oint \frac{\phi}{\mu \cdot S} d \ell=N \cdot i
$$

Where $\phi$ is the leakage flux, $S$ is the cross-sectional area of the path and $\mu$ is the absolute permeability of the iron. The reluctances through the different path of the core may be simply calculated from

$$
\Re=\frac{\ell}{\mu_{0} \cdot \mu_{r} \cdot S}
$$

Where $\ell$ is the length of the path, $\mu_{r}$ is the relative permeability of the material, and $\mu_{0}$ is the permeability of free space.

\section{Phase 1}

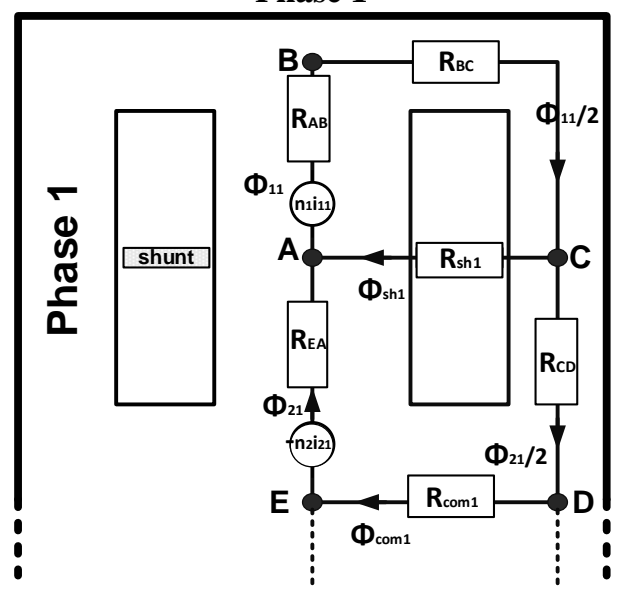

Figure 2. The equivalent magnetic circuit of the shell-type transformer-phase 1

Ampere's circuit law applied around a closed loop (ABCA) can be expressed as:

$$
\mathfrak{R}_{A B} \cdot \phi_{11}+\mathfrak{R}_{B C} \cdot \frac{\phi_{11}}{2}+\mathfrak{R}_{A C} \cdot \phi_{s h 1}=n_{1} i_{11}
$$

Therefore,

$$
\mathfrak{R}_{p 1} \cdot \phi_{11}+\mathfrak{R}_{s h 1} \cdot \phi_{s h 1}=n_{1} i_{11}
$$

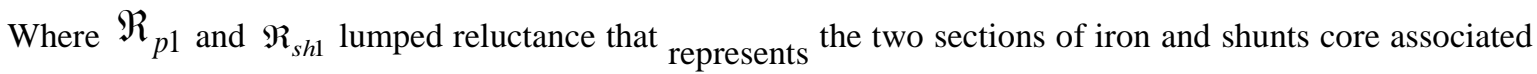
with the path $(\mathrm{ABC})$ and $(\mathrm{AC})$ and carry flux $\phi_{11}$ and $\phi_{s h 1}$ respectively. 
Multiplying the (7) by $\frac{1}{n_{2}}$ gives:

$$
\frac{1}{n_{2}}\left(\Re_{p 1} \cdot \phi_{11}+\Re_{s h 1} \cdot \phi_{s h 1}\right)=\frac{1}{n_{2}}\left(n_{1} i_{11}\right)
$$

Finally, we get the currents equation of the primary side referred to the secondary side:

$$
i_{p 1}^{\prime}+i_{s h 1}^{\prime}=i_{11}^{\prime}
$$

In a similar way, we get the currents equation of the secondary side for loop (ACDEA):

$$
\begin{aligned}
& \mathfrak{R}_{s 1} \cdot \phi_{21}-\mathfrak{R}_{s h 1} \cdot \phi_{s h 1}+\mathfrak{R}_{\text {coml }} \cdot \phi_{c o m l}=-n_{2} i_{21} \\
& i_{s 1}+i_{21}+i_{c o m 1}^{\prime}=i_{s h 1}^{\prime}
\end{aligned}
$$

The primary winding flux $\phi_{11}$ is expressed as the sum of the secondary flux $\phi_{21}$ and the shunt leakage flux $\phi_{s h 1}$ in phase 1 .

$$
\phi_{21}+\phi_{s h 1}=\phi_{11}
$$

Finally, we obtained a voltage equation between primary, secondary and shunt core:

$$
\begin{aligned}
& \frac{d}{d t}\left(\frac{n_{2}^{2}}{\mathfrak{R}_{p 1}} \frac{\mathfrak{R}_{p 1} \cdot \phi_{11}}{n_{2}}\right)=\frac{d}{d t}\left(\frac{n_{2}^{2}}{\mathfrak{R}_{s 1}} \frac{\Re_{s 1} \cdot \phi_{21}}{n_{2}}\right)+\frac{d}{d t}\left(\frac{n_{2}^{2}}{\mathfrak{R}_{s h 1}} \frac{\Re_{s h 1} \cdot \phi_{s h 1}}{n_{2}}\right) \\
& \frac{d}{d t}\left(L_{p 1}^{\prime} \cdot i_{p 1}^{\prime}\right)=\frac{d}{d t}\left(L_{s 1} \cdot i_{s 1}\right)+\frac{d}{d t}\left(L_{s h 1}^{\prime} \cdot i_{s h 1}^{\prime}\right)
\end{aligned}
$$

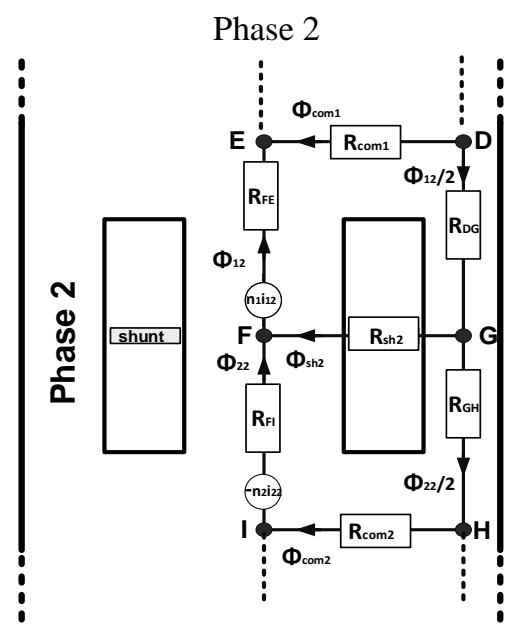

Figure 3. The equivalent magnetic circuit of the shell-type transformer- phase 2

We applied the same laws for the primary side around a closed loop (FGDEF), and we get the following equations:

$$
\begin{aligned}
& \mathfrak{R}_{p 2} \cdot \phi_{12}+\mathfrak{R}_{s h 2} \cdot \phi_{s h 2}-\mathfrak{R}_{c o m 1} \cdot \phi_{c o m 1}=n_{1} i_{12} \\
& i_{p 2}^{\prime}+i_{s h 2}^{\prime}-i_{c o m 1}^{\prime}=i_{12}^{\prime}
\end{aligned}
$$


The application of the same procedure for the secondary side around a closed loop (FGHIF) gives:

$$
\begin{aligned}
& \mathfrak{R}_{s 2} \cdot \phi_{22}-\mathfrak{R}_{s h 2} \cdot \phi_{s h 2}+\mathfrak{R}_{\text {com } 2} \cdot \phi_{\text {com } 2}=-n_{2} i_{22} \\
& i_{s 2}+i_{22}+i_{\text {com } 2}^{\prime}=i_{s h 2}^{\prime}
\end{aligned}
$$

The (15), (17) and the relation between fluxes $\phi_{12}, \phi_{22}$ and $\phi_{s h 2}$ reflecting the conservation of theflows can be expressed as:

$$
\phi_{22}+\phi_{s h 2}=\phi_{12}
$$

Finally, we obtained a voltage equation between primary, secondary and shunt core:

$$
\frac{d}{d t}\left(L_{p 2}^{\prime} \cdot i_{p 2}^{\prime}\right)=\frac{d}{d t}\left(L_{s 2} \cdot i_{s 2}\right)+\frac{d}{d t}\left(L_{s h 2}^{\prime} \cdot i_{s h 2}^{\prime}\right)
$$

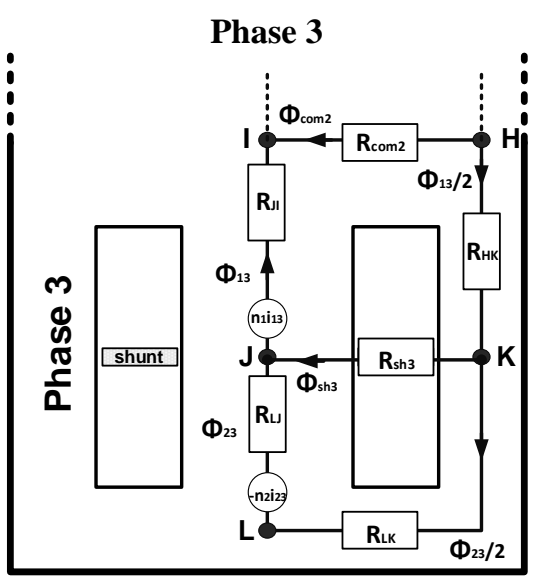

Figure 4. The equivalent magnetic circuit of the shell-type transformer- phase 3

Dividing path (JIHKJ) of an iron core in three partial paths, each of which has a uniform flux, the equation becomes:

$$
\mathfrak{R}_{p 3} \cdot \phi_{13}+\mathfrak{R}_{\text {sh } 3} \cdot \phi_{\text {sh } 3}-\mathfrak{R}_{\text {com } 2} \cdot \phi_{\text {com } 2}=n_{1} i_{13}
$$

The currents equation of the primary side referred to the secondary side:

$$
i_{p 3}^{\prime}+i_{13}^{\prime}-i_{c o m 2}^{\prime}=i_{s h 3}^{\prime}
$$

The application of the same procedure for the main path (JKLJ) gives:

$$
\begin{aligned}
& \mathfrak{R}_{s 3} \cdot \phi_{23}-\mathfrak{R}_{s h 3} \cdot \phi_{s h 3}=-n_{2} i_{23} \\
& i_{s 3}+i_{23}=i_{s h 3}^{\prime}
\end{aligned}
$$

The (21), (23) and the relationship between fluxes $\phi_{13}, \phi_{23}$ and $\phi_{s h 3}$ reflecting the conservation of the flows in phase 3 gives:

$$
\begin{aligned}
& \phi_{23}+\phi_{s h 3}=\phi_{13} \\
& \frac{d}{d t}\left(L_{p 3}^{\prime} \cdot i_{p 3}^{\prime}\right)=\frac{d}{d t}\left(L_{s 3} \cdot i_{s 3}\right)+\frac{d}{d t}\left(L_{s h 3}^{\prime} \cdot i_{s h 3}^{\prime}\right)
\end{aligned}
$$


The previous (8) to (25) leads to draw the equivalent diagram of the three-phase transformer. Thus, we obtain a $\pi$ model of this transformer composed of three nonlinear inductances referred to secondary for each phase. $L_{p j}^{\prime}$ On the primary side, $L_{s j}$ on the secondary side, and $L_{s h j}^{\prime}$ on the shunts side. The inductance $L_{s h j}^{\prime}$ composed of two inductances in parallel. $\left(L_{s h j}^{\prime}\right)^{e}$ Is a fictitious winding of $n_{2}$ turns wound in the air traversed by a current $\left(i_{s h j}^{\prime}\right)^{e}$ and $\left(L_{s h j}^{\prime}\right)^{f}$ is ferromagnetic circuit traversed by a current $\left(i_{s h j}^{\prime}\right)^{f}$. The complete equivalent circuit of transformer referred to secondary is shown in the Figure 5:

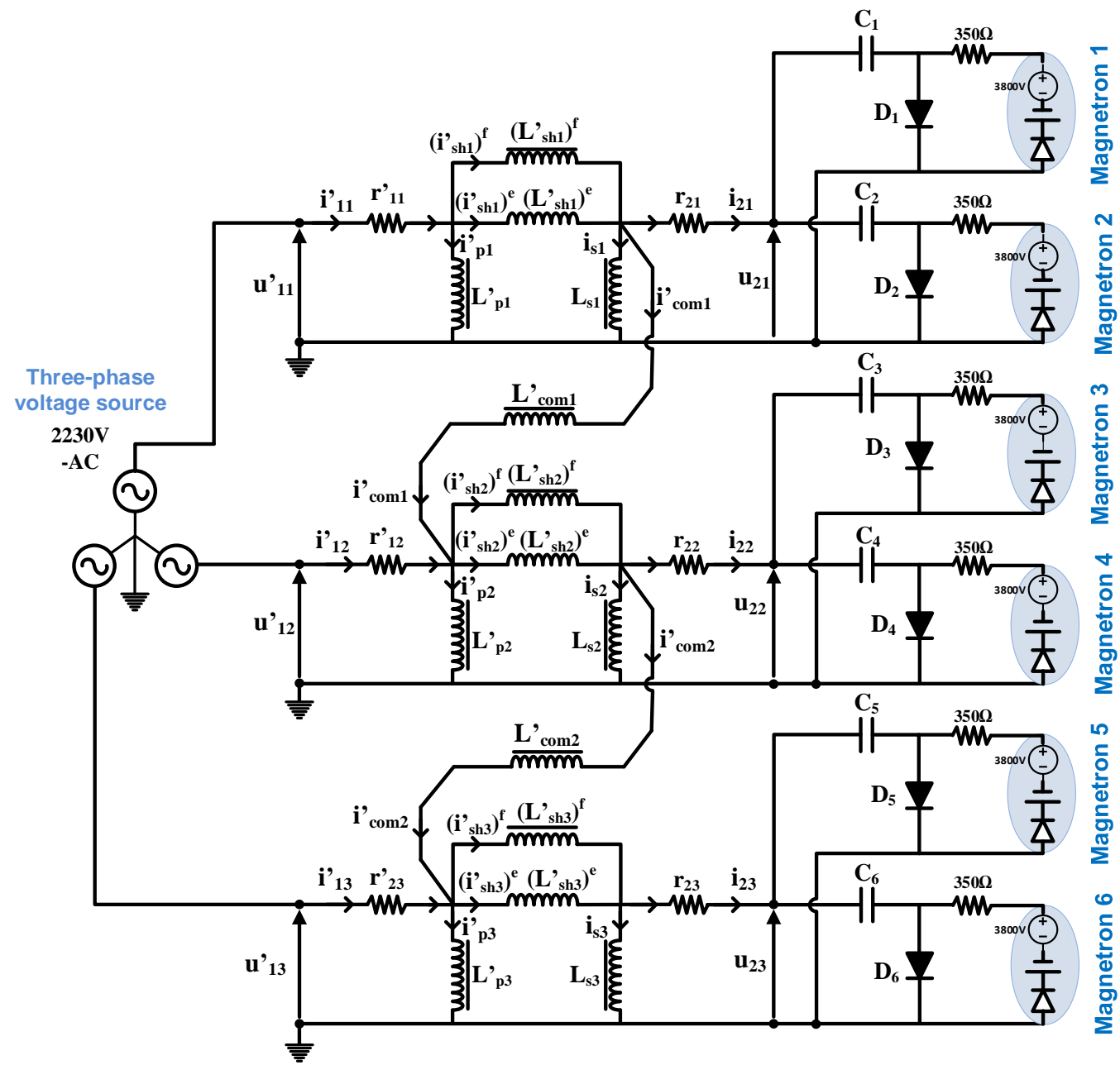

Figure 5. The equivalent electrical model of the new three-phase transformer power supply two magnetrons per phase

\section{RESULTS AND DISCUSSIONS}

The equivalent electric circuit of the transformer $\pi$ model was implemented to simulate the transformer response with MATLAB-Simulink. We compare the results of current and voltage waveforms illustrated in Figure 6 with those recorded during experimental tests in Figure 8. We conclude that the signals form is in consistency with those of the signals form obtained by the experience of a conventional power supply. This confirms the lack of interaction between the powered magnetrons. The operating points of the magnetrons are not disturbed, this is essential for a stabilized current of the power supply. The curves form to confirm that each magnetron can operate properly in nominal operation $\left(\mathrm{u}_{1}=220 \mathrm{~V}\right.$ et $\left.\mathrm{f}=50 \mathrm{~Hz}\right)$, to debit full microwave power $\left(\mathrm{I}_{\text {mean }}=300 \mathrm{~mA}, \mathrm{I}_{\max }=1.2 \mathrm{~A}\right)$, which makes the simulation of this model satisfactory. 

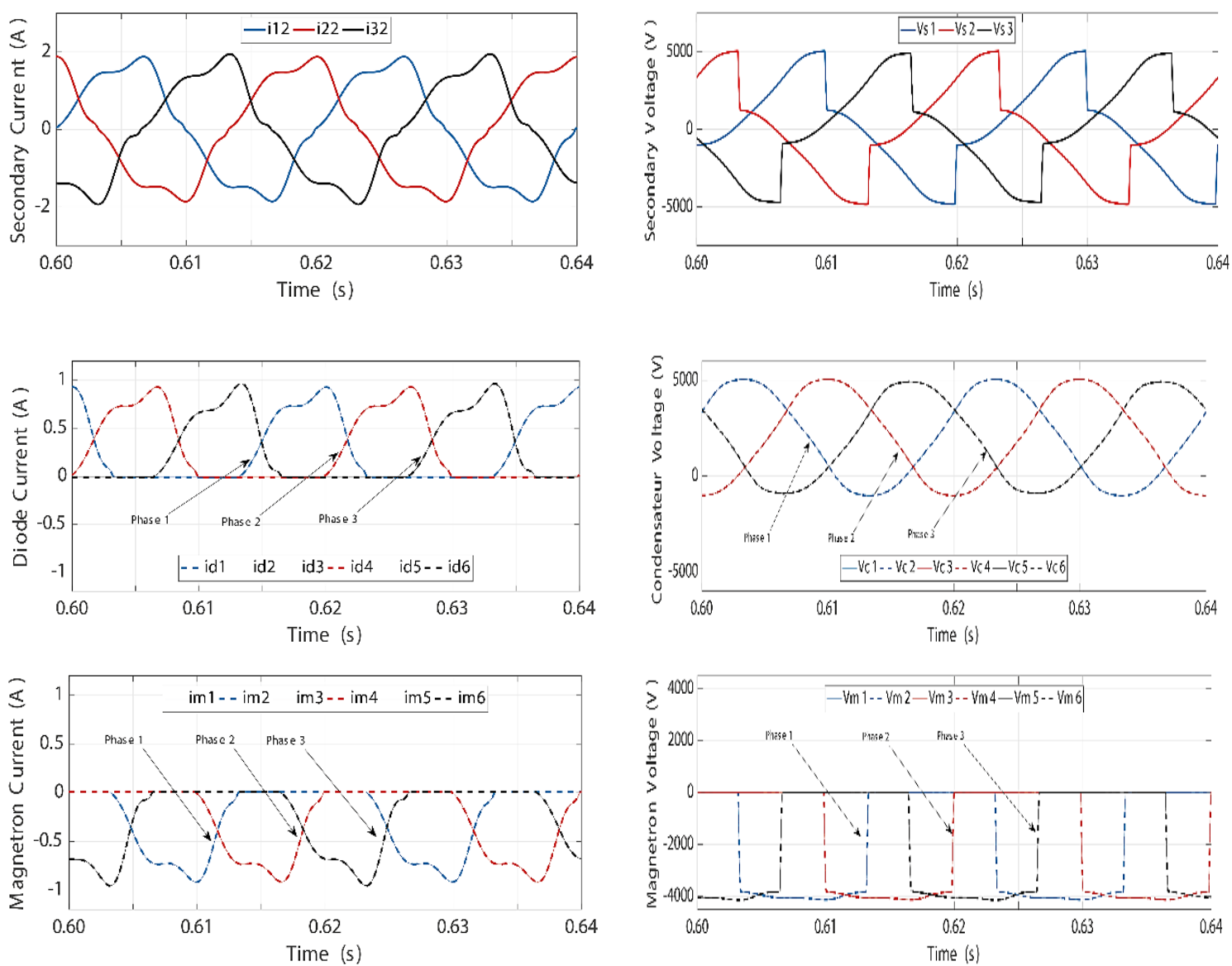

Figure 6. Simulation curves of currents and voltages of the conventional power supply using a three-phase transformer for two magnetrons

\section{EXPERIMENTAL RESULTS}

We sought to integrate the new model of the transformer (with analytic expressions of inductances) in the circuit of the HV supply from the source to the magnetron as shown in Figure 7. The tube microwave is represented by the equivalent diagram deduced from its electric characteristic which is formally similar to a diode of dynamic resistance $R=\frac{\Delta U}{\Delta I}$ neighbor of $350 \mathrm{Ohms}$ and threshold voltage $\mathrm{E}$ of about 3800 Volts. We validate this new model by carrying out tests that have been set up previously on generator microwaves composed of the following elements.

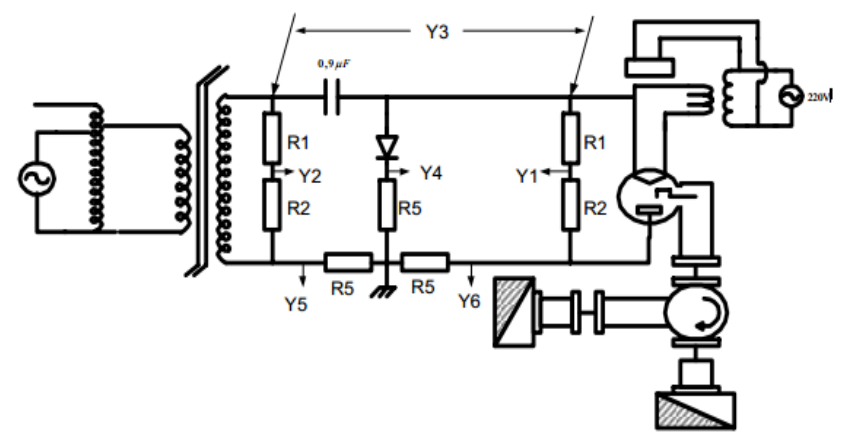

Figure 7. Experimental set up for measuring of the characteristics: currents and voltage of the HV single phase for one magnetron in nominal operation [1] 
As shown in Figure 8, the experimental and simulation results presented in this paper have been obtained and investigated on a laboratory transformer $1650 \mathrm{VA}, f=50 \mathrm{~Hz}$, having the following data:

a. Primary winding resistance: $r_{p}=100 \Omega$; Number of turns $n_{1}=224$ turns

b. Secondary winding resistance: $r_{s}=65 \Omega$; Number of turns $n_{2}=2400$ turns

c. A cell composed of a condenser: $\mathrm{C}=0.9 \mu \mathrm{F}$ and a diode high voltage $\mathrm{DHV}$

d. Leakage inductance of shunt core: $\left(L_{s h j}^{\prime}\right)^{e}=7.81[\mathrm{H}]$

e. $\mathrm{Y}_{1}$ : Magnetron Voltage, $\mathrm{Y}_{2}$ : Secondary Voltage, $\mathrm{Y}_{3}$ : Condensateur Voltage, $\mathrm{Y}_{4}$ : Diode Current, $\mathrm{Y}_{5}$ : Secondary Current, $\mathrm{Y}_{6}$ : Magnetron Current.
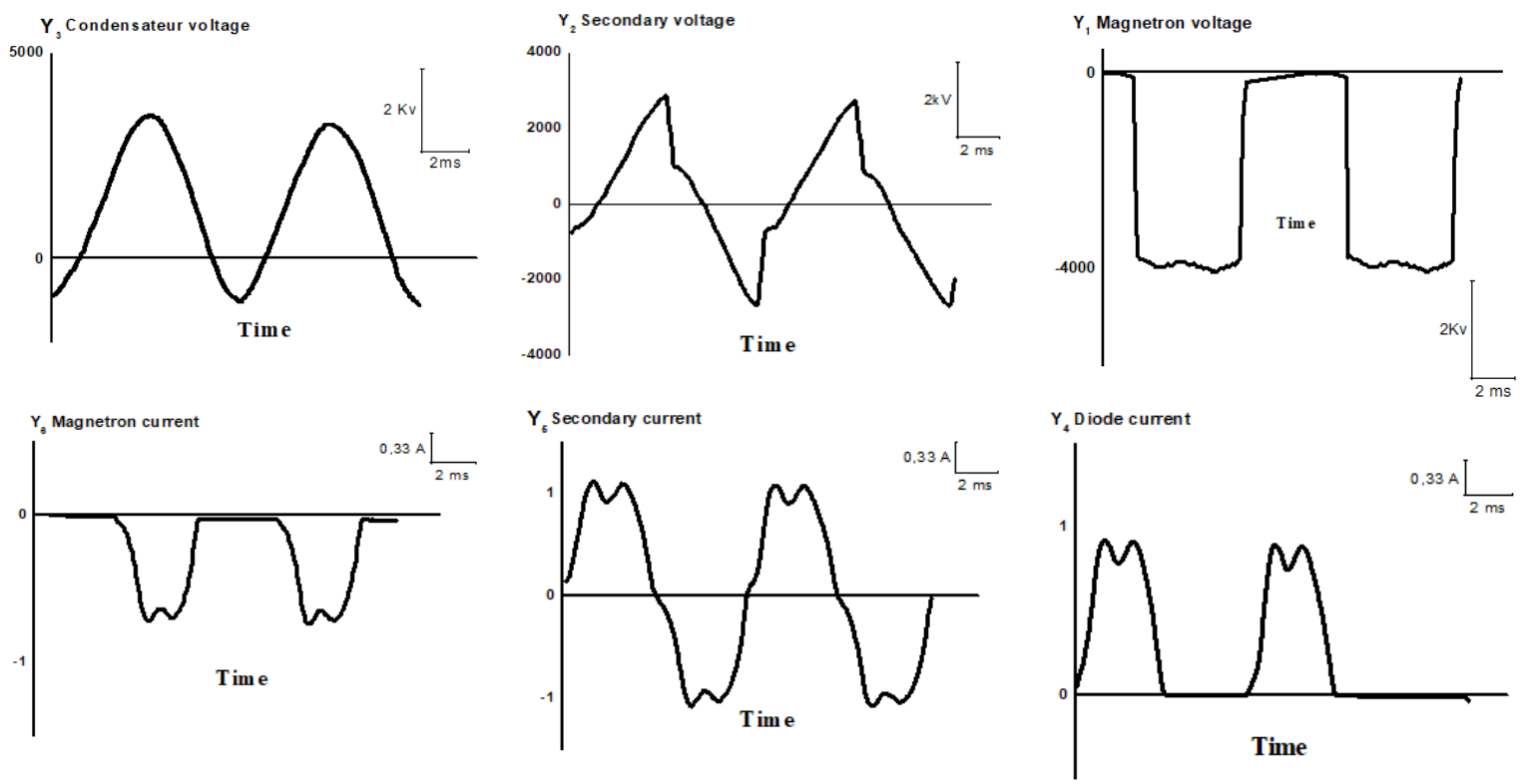

Figure 8. Experimental curves of currents and voltages of the conventional power supply using a single phase transformer for one magnetron

\section{CONCLUSION}

In this paper, detailed models of the three-limb three-phase transformer for power supply HV are presented. The proposed model could give a very useful solution for powering magnetrons in the diverse domain, especially in microwave industrial. For validation, the analysis found results have confirmed the existence of a perfect similarity between the measured and simulated curves from the analytical method. The developed model underlined the importance of this solution. It could supply another load with change various parameters which should define. Although this work is written for the simulation of the three-phase transformer is suitable to study the model optimized to get the best solution with minimum material and space, consequently the cost global of the transformer. These topics are reserved for the new study.

\section{REFERENCES}

[1] M. Chraygane, M. Teissier, A. Jammal, J. Masson, "Modélisation d'un transformateur à shunts magnétiques utilisé dans l'alimentation H.T. d'un générateur micro-ondes à magnétron,” Journal de physique III, pp. 2329-2338, 1994.

[2] M. Bassoui, M. Ferfra and M. Chraygane, "A New Validation Approach of a New Three-Phase High Voltage Power Supply for Microwaves Generators with one Magnetron by Phase," International Journal of Electrical and Computer Engineering (IJECE), vol. 6(1), pp. 1, 2016.

[3] L. M. R. Oliveira and A. J. M. Cardoso, "Modelling and simulation of three-phase power transformers," Proceedings of the 6th International Conference on Modelling and Simulation of Electrical Machines, Converters and Systems (ELECTRIMACS 99), vol. 2/3, pp. 257-262, 1999.

[4] A. Bouzit, M. Chraygane, N. N. Elghazal, M. Fadel, M.Ferfra, and M. Bassou, "Modeling of new single-phase high voltage power supply for industrial microwave generators for $\mathrm{n}=2$ magnetrons," International Journal of Electrical and Computer Engineering (IJECE), vol. 4(2), pp. 223-230, 2014. 
[5] L. M. R. Oliveira and A. J. M. Cardoso, "Three-phase, three-limb, steady-state transformer model: the case of a ynzn connection," Proceedings of the IASTED International Conference (Power and Energy Systems), 2000, pp. 467- 472 .

[6] M. O. Ahmedou, M. Chraygane, and M.Ferfra, "New model validation approach to the leakage flux transformer of a high voltage power supply used for magnetron for the industrial micro-waves generators 800 watts," International Review of Electrical Engineering, vol. 5, pp. 1003-1011, 2010.

[7] E. Naama, M. Chraygane, M. Ferfra, A. Belhaiba, M. Fadel and B. Bahani, "Modeling of New Three-Phase High Voltage Power Supply For Industrial Microwave Generators With One Magnetron Per Phase,"International Journal of Electrical and Computer Engineering (IJECE), vol. 3(2), 2013.

[8] W. Chandrasena, P. McLaren, U. Annakkage, R. Jayasinghe, D. Muthumuni, and E. Dirksu, "Simulation of hysteresis and eddy current effects in a power transformer," Electric Power Systems Research, vol. 76(8), pp. 634-641, 2006.

[9] B. Bahani, A. Bouzit, M. Chraygane, M. Ferfra, N. E. Ghazal, and A. Belhaiba, "Modeling of a new high voltage power supply for microwave generators with three magnetrons," International Journal of Electrical and Computer Engineering (IJECE), vol. 3(2), pp. 164-170, 2013.

[10] S. G. Abdulsalam, W. Xu, W. L. A. Neves, and X. Liu, "Estimation of transformer saturation characteristics from inrush current waveforms," IEEE Transactions on Power Delivery, vol. 21(1), pp. 170-177, 2006.

[11] A. Belhaiba, N. Elghazal, M. Chraygane, M. Ferfra, B. Bahani, and M. O. Ahmedou, "Improved optimization of the nominal functioning of a high voltage power supply $\mathrm{n}=2$ magnetrons for microwaves generator," International Journal of Electrical and Computer Engineering (IJECE), vol. 2(5), pp. 708-716, 2012.

[12] N. Elghazal, A. Belhaiba, M. ChrayganeE, B. Bahani, and M. Ferfra, "New simulation method of new hv power supply for industrial microwave generators with $\mathrm{n}=2$ magnetrons," International Journal of Advanced Computer Science and Applications(IJACSA), vol. 4(12), pp. 55-64, 2013.

[13] M. Fadel, B. Bahani, M. Chraygane, A. Belhaiba, E. G. Naama and M. Ferfra, "Modeling of New Three-Phase High Voltage Power Supply For Industrial Microwave Generators With One Magnetron Per Phase," International Journal of Electrical and Computer Engineering (IJECE), vol. 3(2), 2013.

[14] M. Chraygene, M. Teissier, M. E. Khouza, and B. Hlimi, "vérification expérimentale de la loi de conservation des flux du transformateur à shunts d'une alimentation pour géneérateurs micro-ondes à magnétron destinés aux applications industrielles," RNJCP4-Casablanca, pp. 6-7, 2003.

[15] A. Belhaiba, N. Elghazal, M. Chraygane, M. Ahmedou, and M. Ferfra, "Modeling the power of microwave generator for one magnetron by Matlab-Simulink," International Conference on Multimedia Computing and Systems, 2012, pp. 1024-1028.

[16] H. Outzguinrimt, A. Bouzit, M. Chraygane, M. Lahame, R. Oumghar, and M. Ferfra, "Design and modeling of a new configuration of three-phase transformer for high voltage operation using in microwave industrial," 2018 International Conference on Electronics, Control, Optimization and Computer Science (ICECOCS), pp. 1-6, 2018.

[17] M. Lahame, M. Chraygane, H. Outzguinrimt, R. Batit, R. Oumghar, and M. Ferfra, "Modeling under Matlab by anfis of the three-phase tetrahedral transformer using in microwave generator for three magnetrons per phase," (TELKOMNIKA) Telecommunication, Computing, Electronics and Control, vol. 16(5), pp. 2406-2414, 2018.

[18] B. Bahani, M. Chraygane, M. Ferfra, R. Batit, N. E. Ghazal, A. Belhaiba, and M.Bassoui, "Modeling of a new three phase high voltage power supply for industrial microwave generators with magnetron," International Review on Modelling and Simulations, vol. 8(3), pp. 362-371, 2015.

[19] E. Saraiva, M. Chaves and J. Camacho, "Three-phase transformer representation using FEMM, and a methodology for air gap calculation," 2008 18th International Conference on Electrical Machines, 2008. 